\title{
UN ENFOQUE PRAXIOGRÁFICO A LA BICI-MOVILIDAD EN SANTIAGO DE CHILE. El ciclismo urbano como un logro colectivo
}

\author{
Oriana BERNASCONI*; Maximiliano THAM \\ *Universidad Alberto Hurtado (Chile) \\ obernasc@uahurtado.cl,maxthamt@gmail.com
}

\begin{abstract}
A PRAXIOGRAPHIC APPROACH TO BIKE-MOBILITY IN SANTIAGO, CHILE. Urban cycling as a collective achievement
\end{abstract}

Resumen: En la última década en Santiago de Chile el uso de la bicicleta como medio alternativo de movilidad urbana se ha instalado con fuerza pero ostenta aún un lugar secundario en comparación a otras modalidades de transporte en términos de uso, infraestructura y normativa. Siguiendo un enfoque praxiográfico este artículo explora algunas de las formas en que se organiza y significa la bici-movilidad en dicha ciudad. Realizamos una etnografía distribuida que combinó técnicas etnográficas clásicas y contemporáneas: junto con observaciones en ciclovías del centro de la ciudad y entrevistas con ciclistas, corporalizamos la percepción investigativa mediante la experiencia auto-etnográfica de uno de los autores. A partir del análisis del material empírico describimos un régimen en disputa con otras formas de movilidad que establecen limitaciones y desafíos al ciclismo urbano; una práctica ejercitada, pulida y personalizada; y una cultura de bicimovilidad ambivalente que, por un lado, difunde y valora principios neoliberales como la autonomía, la independencia y la eficiencia del tiempo del individuo y, por el otro, dice representar una ontología política alternativa que subraya la interdependencia y mutua responsabilidad entre humanos y medioambiente. Esta ambivalencia aparece también entre la figura del ciclista individualista y autosuficiente y una práctica que no existe sino con otras personas y materialidades (activistas, atochamientos, compañeros de ruta; otros vehículos, vías, peatones o señalética). Si bien el ciclismo urbano suele definirse como una alternativa de desplazamiento a "tracción humana" demostramos que, en la práctica, la bicimovilidad es un logro colectivo donde, junto con ciclistas con sus discursos, haceres y saberes corporalizados, participan también otras personas, materialidades, objetos, tecnologías, representaciones y regímenes de movilidad.

Abstract: Over the last decade in Santiago, Chile's capital, the use of bicycles as an alternative form of urban mobility has grown steadily, but still holds a secondary position compared to others transport alternatives in terms of use, infrastructure and regulations. Following a praxiographic approach this article explores some of the ways in which urban cycling is organized and signified. We developed a distributed ethnography that combined classical and contemporary ethnographic methods: in addition to observations of bikeways and interviews with cyclists, we draw on the auto-ethnographic experience of one of the authors. The analysis describes a regime in dispute with other forms of mobility that establish limitations and challenges to urban cycling; a trained, polished and personalized practice; and an ambivalent culture of cycling mobility that, on the one hand, spreads and values neoliberal principles such as autonomy, independence and efficient use of individual time and, on the other hand, claims to represent an alternative political ontology that emphasizes the interdependence and responsibility between humans and the environment. This ambivalence also appears between the figure of the individualistic and self-sufficient cyclist and a practice that exists only with other people and materialities (activists, jams, other vehicles, roads, pedestrians, signposting). While urban cycling is often defined as an alternative form of mobility that is "human-powered" we demonstrate that, in practice, urban cycling in Santiago is a collective achievement where, along cyclists -with their discourses, doings and embodied knowledge processes-, there are also involved other people, materialities, objects, technologies, performances and mobility regimes.

Palabras clave: Práctica ciclista. Etnografía distribuida. Auto-etnografía. Materialidades Cycling practice. Distributed ethnography. Auto-ethnography. Materialities 


\section{Introducción: El ciclismo urbano en la red de transporte de Santiago}

En la última década en distintas ciudades de Chile se ha propagado el uso de la bicicleta como un medio alternativo de transporte urbano, alrededor de una preocupación medioambiental pero también en búsqueda de un medio eficiente, certero y libre de las incomodidades que ofrece el sistema público y de las ineficiencias y costos de las alternativas privadas motorizadas. El ciclismo urbano en Santiago de Chile se inserta en un sistema o ensamblaje de transporte en donde las distintas formas de movilidad no necesariamente se relacionan colaborativamente. Por un lado, existe un sistema de transporte público integrado -el Transantiago-, que a ocho años de su implementación es rechazado por el $61 \%$ de la población, debido a sus costos y tiempos de viajes, su mala conectividad y la poco comodidad que entrega, entre otras razones (Collect GFK, 2013). Por otro lado, ha habido un crecimiento exponencial del número de automóviles circulando en las calles, el cual en poco más de diez años ha aumentado en un $90 \%$. De mantenerse esta tasa de crecimiento, tendremos en el futuro un panorama aún más congestionado y contaminante del observado actualmente (Ministerio de Transportes y Telecomunicaciones, 2012). El despliegue del ciclismo urbano en Santiago se debe en parte a estas deficiencias de las otras modalidades de transporte. Distintos estudios miden su expansión sostenida en la ciudad. Los últimos datos sistemáticos indican que el 2012 se realizaban alrededor de 750 mil viajes diarios mediante este modo de actividad (SECTRA, 2014), indicador que según un reporte reciente del Banco Interamericano de Desarrollo ubicaría a Santiago dentro de las tres primeras ciudades de Latinoamérica con mayor uso de la bicicleta como medio de transporte (BID, 2015).

Así, el ciclismo urbano en Santiago se inscribe dentro de un régimen de transporte en tensión: con un sistema público deficitario, un parque automotriz con un crecimiento problemático para la ciudad, y una bici-movilidad también en aumento, pero ocupando un lugar aún marginal y subsidiario tanto a nivel material - por la baja inversión pública y privada que consigna - como normativamente - por la falta de regulación de los derechos y deberes de los ciclistas en particular y la escasa coordinación de las distintas movilidades en las leyes del tránsito, de modo más general. Más aún, dado que Santiago carece de un gobierno metropolitano tanto la infraestructura como las políticas públicas para el ciclismo son gestadas a nivel municipal y su integración territorial depende de las capacidades de coordinación y las prioridades de estas autoridades políticas. En la práctica, entonces, sucede que los ciclistas usan tanto las ciclovías -insuficientes, entrecortadas y mal diseñadas para la circulación- como las calles y veredas y, mientras algunos siguen las normas que regulan a los vehículos motorizados, otros se acoplan a las de los peatones o bien desarrollan una circulación híbrida (en lo que respecta a detenerse en semáforos, doblar por la derecha, mantener velocidades mínimas y máximas, dar prioridad a vehículos menores o peatones, etc.). Por todas estas características se trata de un régimen que deja espacio a la acción e interpretación individual y que demanda múltiples esfuerzos de las personas para volverse ciclistas urbanos, adecuando, manipulando y contraviniendo las disposiciones existentes para generar sus viajes por la ciudad. En suma, en Santiago el ciclismo urbano no es una práctica estabilizada sino en construcción; sujeta a tensiones, conflictos, contingencias y redefiniciones. Este estado magmático vuelve a este régimen de movilidad un caso de estudio interesante para explorar, como hacemos aquí, la práctica del ciclismo urbano en Santiago y obtener aprendizajes para otras ciudades y sociedades. Para ello seguimos un enfoque praxiográfico (Mol, 2003, 2010. Law, 2009. Bernasconi, 2015) y a partir del análisis de entrevistas, recorridos comentados con ciclistas y notas auto-etnográficas, examinamos los elementos materiales, humanos e ideológicos y los procesos prácticos, iterativos y no libre de fricciones que organizan la práctica del ciclismo urbano. Para ello, utilizamos la sociología de la afectación (Gomart; Hennion, 1999. Thrift, 2008) que precisamente permite 
observar los procesos de ajuste del sujeto consigo mismo, con el artefacto y con otros componentes de la práctica.

En la primera parte del artículo revisamos los principales enfoques que se han utilizado para estudiar el ciclismo urbano contemporáneo y exponemos los principios que sustentan nuestro acercamiento a la investigación de la bici-movilidad. La segunda parte expone la metodología utilizada, describe las distintas técnicas de construcción de información, los participantes en el estudio y las estrategias de análisis utilizadas. La tercera sección contiene los resultados. Primero distinguimos la práctica del ciclismo urbano de otras modalidades de uso de la bicicleta y describimos el rol de otros agentes humanos en su gestación y sustentación. Luego abordamos el papel de la bicicleta como máquina, el del cuerpo como espacio pedagógico y las formas de circulación del ciclismo urbano. En las tres temáticas enfocamos la descripción en los distintos componentes de la práctica ciclista y sus modos de relación (ajuste, anticipación, fricción, complementación, etc.). Cerramos la sección discutiendo una cultura de bici-movilidad ambivalente que, por un lado, difunde y valora principios neoliberales como la autonomía, la independencia y la eficiencia del tiempo del individuo y, por el otro, dice representar una ontología política alternativa que subraya la interdependencia y mutua responsabilidad entre humanos y medioambiente. Esta ambivalencia aparece también entre la figura del ciclista individualista y autosuficiente y una práctica que no existe sino con otras personas y materialidades. Finalizamos relacionando nuestro análisis con investigaciones previas y discutiendo en qué sentido el desarrollo de una indagación etnográfica como la propuesta profundiza nuestra comprensión del ciclismo urbano en Santiago de Chile y nos acerca a una conceptualización más compleja de esta forma de movilidad.

\section{Enfoque praxiográfico y etnografía distribuida, corporalizada y móvil}

"Hoy acompaño a María en su recorrido habitual desde su departamento en una comuna del sector oriente de Santiago hasta su trabajo, en el centro de la ciudad. Es mi segundo recorrido comentado para la investigación. Hace aproximadamente dos meses me movilizo en bicicleta, principalmente en recorridos cortos y, en general, acompañado. Para llegar al departamento de María realicé una ruta, consulté google maps y organicé un camino de ciclovías y veredas. Me reúno con María en su departamento, dejo mi bicicleta a cargo del conserje mientras subo a buscarla. La encuentro preparada para salir. Viste su ropa de trabajo -unos pantalones y una blusa-; en una mochila lleva sus pertenencias. Toma su casco dirigiéndose hacia la puerta. Yo la sigo y repito el gesto con mi casco. Bajando las escaleras del edificio María me comunica la ruta que seguiremos: 'parto por la vereda, después tomo [la avenida] Bilbao'. Salimos a la calle, nos subimos a las bicicletas y comenzamos el recorrido transitando por la vereda. María usa una bicicleta urbana morada, con parrilla y ruedas delgadas y, en su percepción, muy liviana. María va delante y yo atrás... me dice 'al principio cuando empecé a tener esta bicicleta, me empecé a sentir súper poco estable, pasaba por una línea y juraba que me iba a caer, que se me iba a pinchar la rueda. Ahora ya no le tengo miedo a los desniveles...' En la vereda pedaleamos con poca intensidad, vamos más lento... tenemos que cruzar con cuidado, en caso que venga un auto... tomamos la calle... me dice que tomemos la derecha... para no encontrarnos con demasiado tráfico... me dice: 'el problema del lado izquierdo son los buses que se detienen en cada paradero, y son grandes, lentas y difíciles de pasar... normalmente me pongo detrás, o a veces las alcanzo a pasar, pero... no siempre, de repente hago todo 
el show... y la micro [el bus] me pasa de nuevo...'... En esta vía también nos topamos con bastantes taxis... "el problema con los taxis -dice María -, es que paran en cualquier parte, y cuando paran pueden dejar gente'... Por la calle avanzamos mucho más rápido que por la vereda... Siento la pendiente en bajada, la bicicleta se aliviana, hago menos esfuerzo... María me cuenta sus estrategias para moverse entre las micros: 'a veces me meto al lado, pero después empiezan a avanzar'... Se interrumpe para instruirme 'ahora en el paradero podemos cruzarla'... María mira para atrás y se da cuenta que no alcanzaremos... 'está difícil, ya no lo hicimos' -sentencia. 'A veces ando más temeraria y me meto, y no freno detrás de la micro [bus]'... Empezamos a avanzar lentamente por el lado derecho de los automóviles, pero hay muy poco espacio y topamos un espejo retrovisor... nos tocan la bocina... seguimos. Nos detenemos por la luz roja de un semáforo. A la izquierda hay una camioneta blanca, cuya cabina nos sobrepasa por el costado. A María le desagradan estas situaciones, estar en la esquina, cuando los autos doblan, porque tienden a no respetarla como vehículo y a doblar a la derecha obligándola a frenar. 'La relación con los autos yo creo que es lo que me da más lata [agobio] y me molesta' (Notas de campo, 17 Octubre 2013, acompañamiento en bicicleta a María, 26 años, Profesional, usuaria hace 5 años).

La investigación acerca de la bicicleta se ha incrementado en los últimos años. En el primer libro temático sobre ciclismo y sociedad, Rosen, Cox y Horton (2007) constatan la ampliación de este campo académico que había estado constituido por cuatro áreas de investigación principales: el análisis de la historia de la bicicleta; el estudio del ciclismo deportivo; el examen de la bicicleta desde la perspectiva de la ingeniería, el diseño y la planificación; y el estudio de los efectos médicos asociados al uso de la bicicleta.

En este escenario, las ciencias sociales han demostrado un expansivo interés por el ciclismo, interrogándolo desde distintos enfoques y preocupaciones. Entre ellos, estudios de caracterización de los ciclistas mediante datos estadísticos según distintos grupos sociodemográficos como género, edad o estatus socio-económico (Caulfield, 2014). Por ejemplo, Steinbach y otros (2011) analizan las características sociales de los ciclistas londinenses, constatando que esa elección no se toma equitativamente entre la población, sino que está mediada por significados de clase y género asociados a hombres blancos de altos ingresos. Otros examinan las razones que motivan a las personas a usar la bicicleta como medio de transporte urbano. Al estudiar las percepciones, actitudes e intenciones de ciclistas, Fernández-Heredia (2014) constata que la conveniencia, flexibilidad y eficiencia son atributos centrales para escoger esta alternativa de movilidad. Complementariamente, utilizado enfoques constructivistas e interpretativos otras investigaciones ahondan en las identidades del ciclista urbano. En esa dirección, Aldred (2013) analiza las estrategias narrativas que utilizan los ciclistas para trabajar sus identidades estigmatizadas y marginales en ambientes dominados por el automóvil y Green y otros (2012) los discursos de viaje de ciclistas, dando cuenta de una identidad moral que signa al ciclismo como una práctica buena y valorable en contraste con la conducción de automóviles, tipificada como inmoral y disfuncional. Este tipo de estudios releva la conciencia ciudadana del ciclista, quien pondría en práctica una responsabilidad ecológica con la ciudad y el ecosistema global, y una responsabilidad del "nuevo ciudadano" que es capaz de conocer y evaluar riesgos y que es competente para viajar en formas que maximizan su independencia, eficiencia y salud.

El trabajo etnográfico de Horton (2006) también subraya los aspectos simbólicos y morales de la práctica del ciclismo, esta vez en un grupo más acotado de activistas medioambientales. La bicicleta es presentada como un objeto con al menos dos dimensiones: un símbolo que aparece con frecuencia en el discurso ambientalista y que representaría la "buena 
sociedad verde"; y un objeto práctico de uso cotidiano en la vida de los activistas, que les permite exhibir de manera concreta a los demás un estilo de vida ecológico. La materialidad de la práctica sería a juicio de Horton central para demostrar, actualizar y mantener su identidad verde.

También existen estudios que relevan las estrategias de los ciclistas para mediar su exposición a la ciudad. La etnografía de Jungnickel y Aldred (2014) describe los dispositivos de audio que los ciclistas usan para producir determinadas sensaciones de viaje, como la relajación y la motivación, conformando un paisaje sensorial y una relación con el ambiente urbano particulares. En lo que respecta al rol del cuerpo y los sentidos en la experiencia del ciclismo, la geografía crítica y cultural de Spinney (2006) muestra cómo los significados de ciertos lugares se construyen corporalmente y en movimiento, a través de un involucramiento práctico y no sólo recurriendo a representaciones simbólicas pre-figuradas del mundo social. Sus etnografías en Francia y Reino Unido describen el esfuerzo progresivo y corporal mediante el cual los ciclistas construyen su subjetividad y se apropian del entorno. En ello el sentido kinésico es central: las sensaciones en los músculos y los receptores del calor del cuerpo guían las operaciones de los otros sentidos, permitiendo a las personas conocer el mundo a través de un involucramiento práctico y corporal con su ambiente (Spinney, 2006).

Un último grupo de investigaciones examina el contexto tecnológico y social en el que se despliega el ciclismo urbano. Utilizando cartografías en las que ciclistas dibujan su ruta más reciente e identifican puntos donde tuvieron experiencias positivas y negativas Snizek y otros (2013) demuestran que los ambientes de tráfico y conflicto, la infraestructura, la densidad urbana, la naturaleza atractiva de paisajes o áreas verdes y la centralidad son variables que se encuentran asociadas al tipo de experiencia de movilidad que tienen los ciclistas. Respaldando esa evidencia, se ha reportado que la presencia de ciclovías y otros recursos materiales como estacionamientos e iluminación promueven el transporte en bicicleta, subrayando que la práctica no sólo depende de las características socio-demográficas de sus usuarios, sino que también de la infraestructura (Dill; Carr, 2003) y de las políticas locales relacionadas con el uso de la bicicleta (Rietveld; Daniel, 2004).

Es en este campo académico donde insertamos nuestra investigación. Intentamos nutrirnos y dialogar con las investigaciones existentes para desarrollar una aproximación integrada al estudio de la bici-movilidad en Santiago. Para ello seguimos un enfoque praxiográfico (Mol, 2003, 2010. Law, 2009. Bernasconi, 2015) y desarrollamos una modalidad de investigación etnográfica distribuida, corporalizada y móvil. ${ }^{1}$ Este enfoque "describe como los objetos o entidades son hechos reales a través de las prácticas que los constituyen" (Mol, 2003: 31), asumiendo que las realidades son producidas y no sólo explicadas por prácticas, discursos y creencias (Mol, 2003: 59). Para el etnógrafo seguir este enfoque implica abandonar lo que Mol denomina 'contemplación descorporalizada': en vez de poner la etnografía al servicio de la observación de un objeto desde varias perspectivas, de modo de recoger y comprender las diversas estructuras epistemológicas con que éste se piensa o usa, el analista praxiográfico seguirá sus objetos por las múltiples, pequeñas y cotidianas actividades que los conforman, intentando comprender cómo ciertas ontologías son hechas existir y sostenidas en el tiempo (Hadders, 2009). Así, nuestra etnografía enfatizó la identificación de una serie de elementos heterogéneos -kinésicos, emocionales, técnicos, materiales, cognitivos, discursivos y simbólicos- y su modo de relación en la composición y estabilización -con interferencias, de manera inacabada y parcial- del ciclismo urbano como una práctica más o menos compartida e identificable en esta ciudad.

\footnotetext{
1 El ciclismo urbano fue una de las prácticas estudiadas en el marco de un proyecto de investigación mayor sobre sociologías del individuo, que examinó cómo los "individuos ecológicos" son hechos existir en determinados agenciamientos socio-materiales. Proyecto Fondecyt $\mathrm{N}^{\circ} 11110459$ apoyado por el Fondo Nacional de Desarrollo de la Ciencia y la Tecnología de Chile a cargo de Oriana Bernasconi.
} 
El extracto de las notas del acompañamiento a María que abre esta sección da cuenta de cómo actúan algunos de estos componentes y cómo afecta, complementa o interfiere el trabajo de los otros y la figuración misma del ciclismo en este viaje: una ciclista que comparte sus aprendizajes, identifica sus habilidades (poder estabilizarse, no pinchar, saber adelantar buses); pero también el papel que juega la bicicleta (con ruedas delgadas, pero liviana); las veredas con desniveles (que definen la intensidad del pedaleo); las vías pobladas de automóviles (que circunscriben el espacio -intersticial, marginal- que puede ocupar el ciclista, en el lado derecho de una calle).

Para relevar el rol activo de elementos heterogéneos en la asunción y ejecución de la práctica ciclista, utilizamos la sociología de la afectación (attachment) (Gomart; Hennion, 1999. Thrift, 2008). Ella refiere al estudio de los procesos prácticos e iterativos mediante los cual actores y entidades aprenden a 'afectarse' es decir, a participar, modularse, componerse y describirse cuando entran en relación. Estos procesos de ajuste involucran actividad con respecto a uno mismo y también a otros elementos (sean éstos humanos, naturales o materiales) y, generalmente, requieren de considerable esfuerzo. En este sentido, afectarse es, como diría Garfinkel (1967), un "logro práctico". En nuestro caso, proponemos, se trata de un logro o trabajo colectivo de ciclistas avezados, activistas, ciclistas en ciernes, automovilistas, taxistas, peatones, climas, temperatura y complexiones corporales, ciclovías, señalética urbana, cicletada, entre muchos otros componentes.

A la base de este enfoque se hayan dos principios que movilizamos en nuestra etnografía. Por una parte, el de ampliar la capacidad de agencia (entendida como capacidad de movilización de la acción) a los objetos y la naturaleza y, por la otra, el de utilizar el mismo repertorio explicativo para abordar los aspectos técnicos y los sociales del ciclismo urbano. A esto se le denomina principio de simetría (Callon, 1995). Usualmente a la tecnología no se le otorga poder explicativo sobre los fenómenos sociales mientras que se la suele considerar como desprovista de componentes sociales. Nuestra intención en este trabajo fue observar la tecnología como un híbrido socio-técnico y centrar la mirada en la práctica del ciclismo urbano de modo de ampliar los análisis convencionales incluyendo el rol de las materialidades junto con el de los humanos, y así examinar qué es lo que hacen juntos para componer esta práctica de movilidad urbana. ${ }^{2}$

El enfoque etnográfico nos permitió indagar la práctica del ciclismo urbano como "el efecto de una red fluida de relaciones y como un objeto múltiple que gestiona esas diversas existencias" (Bernasconi, 2015: 215). Desarrollamos una estrategia cercana a la etnografía multi-sitio (Marcus, 1995. Bernasconi, 2013) mediante la cual más que seguir a un actor o a un tipo de actores a través del tiempo "y en lugares y situaciones locales", priorizamos por identificar distintos sitios, procesos y agentes que componen la práctica para luego verlos actuar y relacionarse en un tiempo-espacio difuso (Marcus, 1995: 1). Se trató entonces de una etnografía distribuida, morfológica, focalizada en la articulación de los diversos elementos de la práctica. Para ello construimos un corpus de material empírico mediante:

- Entrevistas semi-estructuradas a 14 personas que utilizaban la bicicleta como medio de transporte. Siete hombres y siete mujeres, de entre 24 y 60 años, la mayoría con estudios universitarios, que llevaban movilizándose en bicicleta entre uno y 10 años por un radio que abarca los sectores centro y oriente de Santiago ${ }^{3}$, que son los mejor abastecidos de infraestructura de transporte (ciclovías, metro, buses). Algunos de ellos se desempeñaban como activistas en organizaciones ciclistas de la sociedad civil. La selección de casos apuntó a

2 Para conocer más detalles de este acercamiento revisar (Bernasconi, 2015).

3 Si bien esta selección de casos puede limitar los hallazgos en torno a las experiencias desiguales de movilidad según nivel educativo o socio-económico, en este trabajo priorizamos el análisis de la dimensión desigual del ciclismo en relación con otras modalidades de transporte. 
obtener diversidad de situaciones y para contactarlos usamos nuestras redes sociales. Las entrevistas tuvieron lugar en casas o parques, en ocasiones después de haber andado en bicicleta. Las entrevistas exploraron de manera amplia la historia personal con la bicicleta, los recursos y aprendizajes necesarios para su uso y las motivaciones, dificultades, significados y efectos asociados a la práctica.

- Revisión documental. Recolectamos y analizamos documentos que contenían descripciones y visiones del uso de la bicicleta y del ciclista en Santiago. Revisamos documentos de la política pública y la planificación urbana (leyes de tránsito, manuales de construcción de ciclovías, planes maestros, etc.) y de la sociedad civil para identificar las "prácticas discursivas" (Callon, 2008) que categorizan y definen al ciclista en la ciudad.

- Asistencia y registro de "eventos ciclistas". Observamos cómo se movilizan descripciones y justificaciones del ciclismo urbano en otras situaciones sociales: asistimos a conferencias y seminarios sobre movilidad urbana organizados por el Estado, por municipalidades y por organizaciones de la sociedad civil, así como situaciones de sociabilidad de "aficionados" (Hennion, 2001) a la bicicleta, tanto reales (ferias, talleres de mecánica colectivos y cicletadas) como virtuales (páginas webs y redes sociales).

- Recorridos con ciclistas urbanos. Con algunos de los entrevistados ensayamos una actividad inspirada en la "etnografía video-móvil" (Spinney, 2011), en la que acompañamos al ciclista en uno de sus trayectos, conversando sobre (y observando las) prácticas involucradas y la experiencia configurada en esa situación concreta de movilidad. Como indican Watts y Urry (2008), “una etnografía móvil involucra viajar con personas y cosas, participando en su continuo cambio a través del tiempo, del espacio, y de las relaciones con otros" (867). En este sentido, como advierte Spinney (2011) el uso del video fue pensado para el proceso de análisis y evocar para el acto de comunicación de los resultados a las audiencias, algunos de los detalles de la práctica sometida a estudio, especialmente la manera en que los elementos que la componen se enlazan, complementan, superponen o interfieren una y otra vez en el tiempo y en el espacio del viaje, y la manera en que el ciclista como el gran concertista, se coordina con estos componentes y los significa discursiva, corporal o kinésicamente.

- Auto-etnografía. Por último, decidimos desarrollar un acercamiento experiencial y "en primera persona" mediante técnicas "auto-etnográficas" (Ellis y otros, 2010). Uno de los investigadores, que solía usar otras formas de movilidad por la ciudad, hizo el ejercicio de convertirse en ciclista, descubriendo los aprendizajes, las dificultades y emociones asociadas a este modo de actividad y a este tipo de individuo en su propia experiencia e incorporando o al menos ensayando en su práctica ciclista las distinciones y modos de realización que iba recogiendo en el trabajo de campo.

En suma, combinando técnicas y estrategias etnográficas clásicas y contemporáneas tradujimos al ejercicio empírico los postulados del enfoque praxiográfico que enmarca la investigación, para observar, hablar y corporalizar la percepción etnográfica de modo de practicar, aprender y describir el ciclismo urbano en su configuración práctica y móvil.

\section{El ciclismo urbano como alternativa de movilidad}

El ciclismo urbano (en adelante CU) se inserta en Santiago en un circuito de movilidad en tensión, compuesto no sólo por bicicletas, sino también por buses, automóviles, motos, peatones. Dentro de ese entramado de transporte, la bicicleta es activada de una forma particular para configurar el ciclismo urbano. Como alternativa de movilidad, la bicicleta es adquirida, preparada para el uso y puesta en actividad como medio o conector espacial: permite el desplazamiento de los seres humanos entre distintos puntos de la ciudad. En ello, ciertos elementos adquieren preeminencia: un punto de partida y otro de destino, una ruta o trayecto que se elige, se prueba, se corrige, se aprende a conocer y a manejar con eficiencia; 
un lugar donde estacionar el vehículo, un equipamiento que asegure comodidad (poleras dry fit, mascarilla o pañuelo, pantalones que no se enganchen en los pedales, calzado cómodo) y también la seguridad del ciclista y de la máquina (casco, luces, campanilla, refractores, el candado "u-lock"). Dado el propósito de movilidad, el ciclista urbano también requiere equiparse con ciertas capacidades como saber parchar la bicicleta por sí mismo, de modo de poder continuar el recorrido si se enfrenta a este contratiempo.

Participando del CU, la bicicleta adquiere realidad diferenciándose de otros usos que tiene en la ciudad: los recreativos y deportivos, por ejemplo. Tomar la bicicleta el día sábado para subir un cerro de la ciudad y luego lanzarse avenida abajo, es considerada una actividad deportiva:

"Después en el liceo la dejé como dos años y la retomé cuando iba en tercero medio. Ahí ya la ocupaba más como deporte. Me iba a los cerros de Huechuraba, llegaba hasta la punta del cerro y me lanzaba sin casco (risas), por la avenida. Ahí era una cuestión más deportiva" (Javiera, 26 años, Licenciada en Historia, usuaria hace 2 años).

Pese a que nuestros informantes transitan varios kilómetros diarios en bicicleta, su uso en modalidad CU no se califica como una actividad física o deportiva que responda en primer lugar a una necesidad de ejercicio, aunque los ciclistas lo suelan considerar un beneficio adicional. La decisión pasa porque, ubicado en un lugar de la ciudad, el transporte en bicicleta dentro de cierto radio es considerado una alternativa económica, eficiente, suficientemente segura, cómoda, autónoma, limpia y agradable de practicar. Como explica Sergio,

"Cuando con la Carla empezamos a vivir en el centro nos empezó a pasar... dos cosas, nos fuimos a vivir al centro y dejé de ser escolar, por ende, en vez de pagar 120, 130 pesos tuve que pagar $600 \mathrm{y}$ tanto por trayecto [en el metro]... Sentía que era una estafa... No puedes caminar tres estaciones, o sea, puedes hacerlo pero no tienes el tiempo pa' hacerlo... Entonces, tomé la decisión racional de comprarme una bicicleta... fue así... desde la lógica no más de la movilización [...] algo útil y barato... liviano, algo más simple. Y me compré una bicicleta, una single speed, eh, y [...] dije ya, me voy a comprar la bicicleta y... de aquí pa' adelante, voy movilizarme solo en bicicleta o voy a intentarlo, entonces, compré casco, luces, le puse una parrilla a la bici... compré todo lo que necesitaba, el bombín... y ahí me empecé a movilizar en bicicleta (Sergio, 27 años, Profesor de Lenguaje, usuario hace 2 años).

Elementos centrales del uso de la bicicleta en modalidad CU como un destino, una ruta o trayecto eficiente que asegure un tiempo de viaje, pierden relevancia en la modalidad de paseo o recreativa: donde el énfasis está en "perderse" por la ciudad, "sin tiempo", para disfrutar el momento, dejándose sorprender y llevar por el entorno.

\section{El rol de otros para hacer factible la experiencia}

A pesar de que se caracterice al CU como una práctica en la que resuenan los valores del individualismo, la autonomía y la auto-suficiencia (Rosen y otros, 2007: 5), la afectación del ciclista a su bicicleta y a esta forma de movilidad es mediada por lo que otras personas dicen y hacen. "El amigo", "el compañero de estudios" o "el colega" aparecen como una de las condiciones de posibilidad del CU: presentan la bicicleta, invitan a su uso, acompañan en la ruta, introducen en la práctica, difunde sus beneficios y sirve de modelo de aprendizaje. Damián comenta: 
"Partí exclusivamente yéndome a la universidad. Como te mencioné, llegó un amigo mío y me dijo, "sabes que vámonos en bici, un día te paso a recoger" y nos fuimos juntos. La primera vez como que me apadrino en ese sentido" (Damián, 24 años, Diseñador, usuario hace 5 años).

Para María, estas mediaciones fueron centrales para devenir ciclista:

"Yo jamás fui ciclista y fue como: ya, voy a ser ciclista. Y tengo una compañera en la pega [trabajo] que anda en bici y ella me orientó: 'ya, cómprate estas luces, esta máscara es súper bacán [buena], este casco' .Y le hice caso (...) de orientarme a través de gente que yo sé que maneja el tema. (María, 26 años, Profesional, Usuaria hace 5 años).

Nuestros esfuerzos auto-etnográficos también nos pusieron en contacto con la dimensión colectiva de esta práctica. Uno de los investigadores adoptó esta forma de movilidad para trasportarse y para acompañar a los ciclistas en sus recorridos. Un "actor torpe" (Latour, 2005: 119), vivenciando en primera persona el carácter relacional, corporal, técnico y emocional del ciclismo que los informantes comunicaban:

"Nos preparamos para comenzar el recorrido, nos subimos a nuestras bicicletas... vamos por un bandejón central hacia el oriente... es una suerte de ciclovía, con una franja blanca pintada que marca la vía ciclista... llegamos a la calle y cruzamos por el semáforo peatonal... Pedro me dice 'este punto es difícil porque hay mucho auto, mucha gente'... para mí es un trayecto nuevo, no tomé esa calle al venir... Pedro me indica el recorrido con sus manos y me dice 'este es el camino que tomo para llegar a la ciclovía... me acomoda su alternativa, es más directa porque implica cambiar menos entre vereda, ciclovía y calle... reconozco que aprendo al hacer los acompañamientos... pienso que es distinta la experiencia de ir acompañado que ir solo... siendo novicio me siento más seguro siguiendo a otro, tengo más "tips", aprendo nuevos recorridos" (Notas de campo, Acompañamiento en bicicleta a Pedro, 03-12-2013).
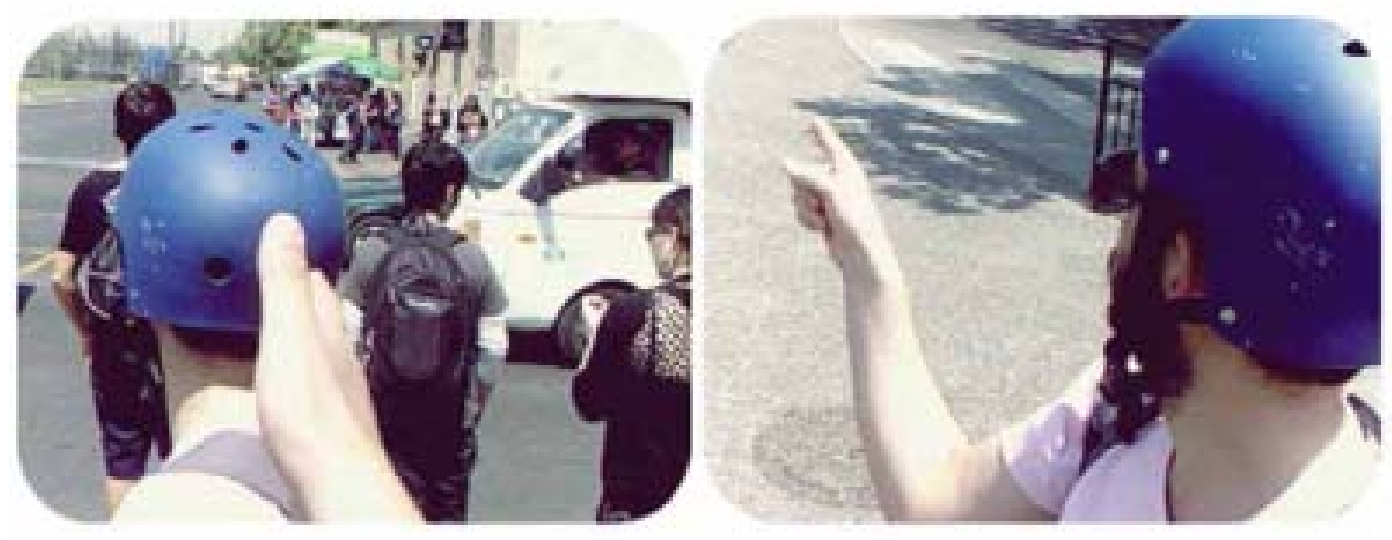

Figura 1. Fotografías del etnógrafo durante un acompañamiento 
Nuestros entrevistados nos enseñaron la importancia de los objetos y materiales involucrados: las luces y los frenos, la detección de las piedras que pinchan las ruedas, la capacidad de sopesar la magnitud del artefacto en relación a la del cuerpo propio "quizás tu bicicleta es muy grande" o la capacidad de distinguir y precisar la distancia apropiada de nuestros pies al piso una vez montados en la bicicleta "tienes que subir tu asiento". Nos compartieron los múltiples procedimientos que implementan para garantizar un viaje exitoso y placentero, como las estrategias para evadir microbuses, taxistas y autos; o la personalización de trayectos:

“Ayer después de la entrevista conversaba con Carla... una de las participantes de la investigación... me pregunta cómo voy con esto de andar en bicicleta... le cuento mi ruta de ciclovías... me dice que para ella las ciclovías son muy lentas y que en ellas uno se cansa más... Me cuenta su ruta y me invita a usarla, que vaya por una calle donde se 'forma un espacio'... donde los autos no te molestan... que va a ser mucho más rápida... me convence y pienso en probarla al día siguiente" (Notas de campo, 21-08-2013).

Pese a que a la movilidad urbana en bicicleta se realiza en forma individual, al acompañar ciclistas, hablando y aprendiendo de ellos y practicando esta forma de movilidad constatamos que en su realización intervienen y resuenan muchas otras personas que sirven de modelo, fomentan la práctica, nos enseñan a reparar en distinciones u observaciones que hasta ese momento no existían en nuestro repertorio y facilitan una relación con nuestro propio cuerpo y la ciudad que se va ajustando con la práctica.

\section{El lugar de la máquina}

Como el CU es fundamentalmente una modalidad electiva, es decir, que se prioriza frente a otras alternativas de transporte posibles como el sistema público o el automóvil, su práctica debe ser agradable. En consecuencia, los ciclistas invierten en una serie de operaciones o actividades para producir una experiencia grata. Hay quienes buscan llegar tranquilos y, por lo tanto, evitan manejar en horas punta, usar calles congestionadas o de gran flujo; otros priorizan el transitar seguros y se protegen con equipamiento, iluminación o la selección de las vías de tránsito; hay quienes disfrutan de la velocidad y la complementación entre el cuerpo y la máquina y, entonces, buscan la tecnología que le permita este tipo de experiencia. Un elemento común a este tipo de producción de la experiencia es el ajuste a la bicicleta una vez definida la modalidad de viaje que se quiere adoptar. En este sentido el ciclista no sólo sintoniza su actividad con la actividad de otras personas -ciclistas o no-; también es central su ajuste con la máquina, la bicicleta.

La relevancia de este ajuste entre individuo y máquina es tal que en varias ocasiones esta relación con la bicicleta se volvió el eje articulador del relato de los ciclistas que entrevistamos: la adquisición de nuevas bicicletas y el proceso de aprendizaje de su uso operan en estos relatos como marcadores de hitos, etapas o necesidades que la actividad va creando. La mayoría de nuestros informantes reporta uno o dos cambios de bicicleta en su trayectoria como ciclista urbano, en el intento por acoplar la tecnología al modo de actividad de su gusto. Y es que la bicicleta afecta el viaje mismo: su peso, la presencia o no de amortiguadores, el manubrio, el mecanismo de freno o el de pedaleo modulan la experiencia de movilidad por la ciudad:

"Y ahora nada, tengo una bici, la tengo hace un año...entremedio tuve otra, una bayonet que era así como...grande...con amortiguación y todo, pero era muy pesada, así que ahora pa mí lo más importante es que sea liviana, que sea 

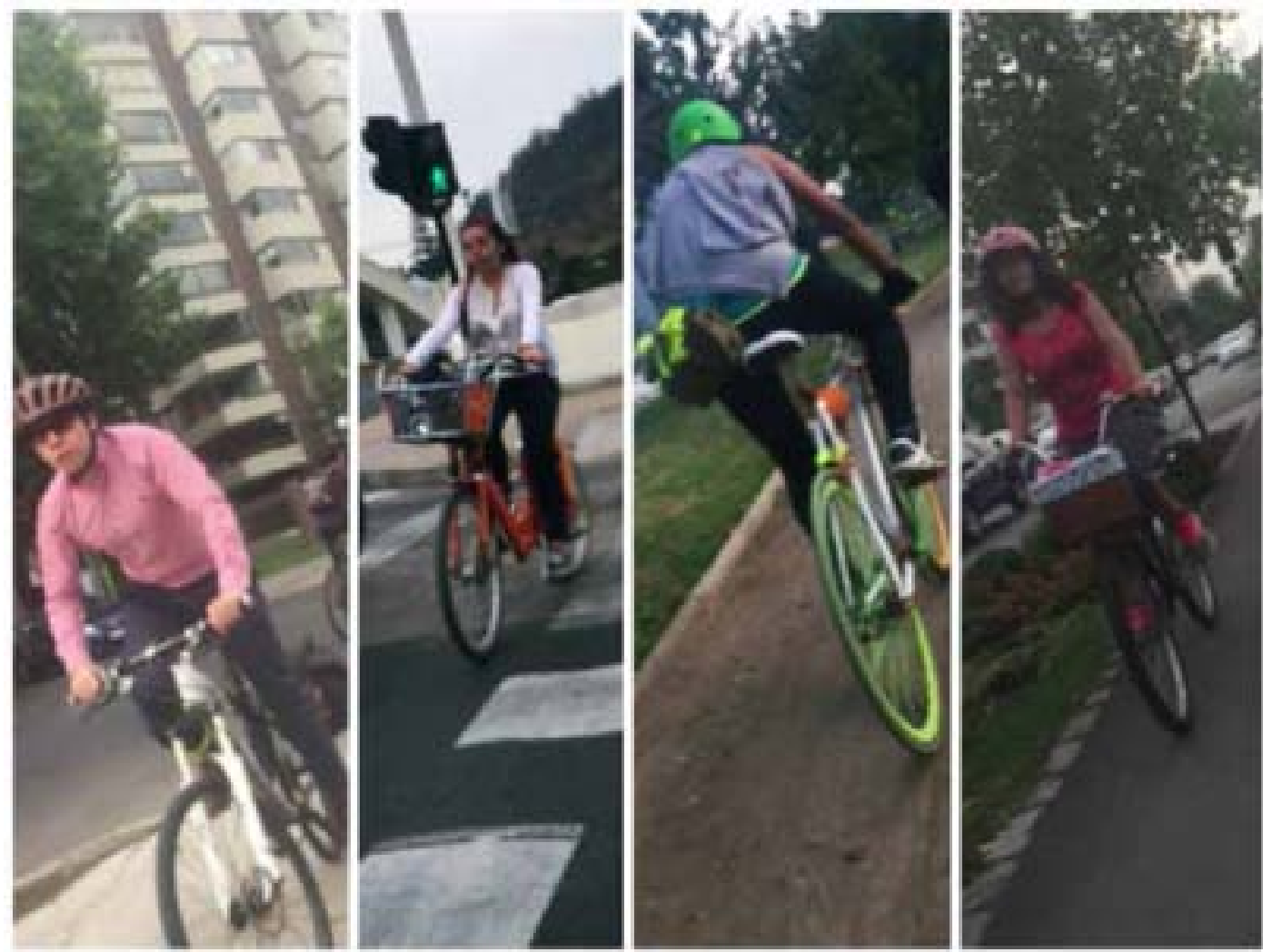

Figura 2. Fotografías extraídas de video-grabaciones durante la observación de ciclovías y calles. De izquierda a derecha cuatro tipos de bicicleta que circulan en el radio estudiado: mountain bikes, públicas, pisteras y de paseo.

transitable, o sea, echo un poquito de menos que no tenga nada de amortiguación adelante porque igual las muñecas se resienten bajando o subiendo veredas todo el rato. Pero sí, hace un año te diría, como que ahora mi lógica es una bicicleta austera, que sea lo más liviana posible pero que no sea una bicicleta súper apetecida, súper cool... también [por] el tema del robo" (Ana, 35 años, Estudiante de Postgrado, usuaria hace 7 años).

En este fragmento observamos cómo las propiedades materiales de la bicicleta ("que sea liviana") se ajustan a las necesidades de movilidad de Ana ("que sea transitable"), y cómo el logro de estos ajustes marca etapas (“ahora para mí”) y genera efectos físicos (muñecas resentidas). En este sentido, una bicicleta equivocada puede frustrar el viaje y desmoronar en conjunto este modo de actividad. Y encontrar la bicicleta apropiada puede llevar tiempo. Simón lo vivió:

"Empecé a irme en bicicleta y yo llegaba y yo transpiraba así a la u[niversidad], y eso ya era un poquito incómodo... después me devolvía en bicicleta y de vuelta venía así sopeadísimo [muy mojado] asi kilómetros y yo quedaba raja [extenuado] y sopeado" (Simón, 35 años, Ingeniero Comercial, usuario hace un año).

Los efectos adversos que Simón comenzó a asociar a la movilidad en bicicleta (llegar 
muy cansado y transpirado a su destino) hicieron que eventualmente abandonara esta alternativa de transporte, para retomarla años después para dirigirse a su trabajo. Sólo en ese momento identificaría que era la materialidad misma de la bicicleta la que años atrás le impedía lograr el viaje cómodo y agradable que ahora experimentaba: la bicicleta anterior era pesada como un "tanque italiano".

Pero no sólo es importante tener la máquina adecuada, también hay que aprender a usarla, conocerla, "leerla", es decir, decodificarla, para obtener de ella el uso para la que está diseñada. En este sentido, el vínculo con la bicicleta es también de aprendizaje técnico y corporal que, como explica Sergio, trae aparejado la generación de creencias como la confianza en el correcto desempeño de la práctica y la capacidad de asumir situaciones imprevistas:

"Yo con esta bicicleta recién estoy adquiriendo confianza, porque es una bicicleta mucho más difícil, y además yo le agregué dificultad, porque es un piñón fijo... entonces yo tengo que parar con los pies y con todo mi cuerpo, mis pies van metidos en unos pedales, eso quiere decir que si yo me caigo, lo más probable es que/ Te vayas con toda la bici. Yo igual tengo un freno de salvavidas... pero si no, voy controlando con el cuerpo, y eso hace que yo haga un trabajo físico mucho mejor, implica todo mi cuerpo la cadencia y el ritmo es mucho mejor, no me canso tanto porque siempre estoy pedaleando, siempre estoy haciendo ejercicio físico. Pero eso igual dentro de la ciudad implica un mayor riesgo. Esta bicicleta es distinta, como es nueva, la estoy conociendo y de a poco voy adquiriendo más riesgos" (Sergio, 27 años, Profesor de Lenguaje, usuario hace 2 años).

\section{La pedagogía del cuerpo}

El CU requiere también de un proceso de descubrimiento, entrenamiento y ajuste físico y mental del propio cuerpo del ciclista en varios niveles. El CU es intensivo en el uso de los sentidos -vista y oído especialmente. Con ellos el ciclista registra y actualiza la marcha de acuerdo a los elementos que pudieran interceptar el trayecto. Complementariamente, hay también un entrenamiento orientado a conocer los repertorios de reacciones de los otros tipos de agentes de modo de poder anticiparlos cuando interfieren en el radio de actividad del ciclista: "el peatón no te ve", "el automovilista suele virar por sobre la ciclovía lateral sin mirar si vienen bicicletas" o "los taxis al detenerse por pasajeros suelen abrir la puerta sin mirar alrededor":

\footnotetext{
"Fue más que nada, como lo que uno primero siente al momento de transformarse en un ciclista, que es como el miedo a salir a la calle, a enfrentarse con lo que son los vehículos, las micros [buses], los camiones, pero son cosas que después uno va como asimilando y se va acostumbrando" (Javiera, 26 años, Licenciada en Historia, usuaria hace 2 años, extracto recorrido comentado desde Plaza Italia a Ñũ̃oa, 12.01.2014, 10:30 -11:15 am)
}

También sucede un proceso de ajuste mental. Varios informantes reportan que al iniciarse tenían la idea de que todo quedaba demasiado lejos, y que el esfuerzo iba a ser extenuante. Practicando tuvieron una experiencia distinta; las distancias "se acortaron" y sus sensaciones físicas les indicaron que la exigencia corporal no era tan extraordinaria.

El ajuste mental requiere asimismo entrenar la capacidad de concentración para no distraerse y aprender a generar ciertas modalidades de atención vigilante, por ejemplo, gestos pequeños, certeros y seguros que se puedan realizar en movimiento sin desafiar el equilibrio y que permiten registrar elementos cercanos con los que coordinar el movimiento, a los que 

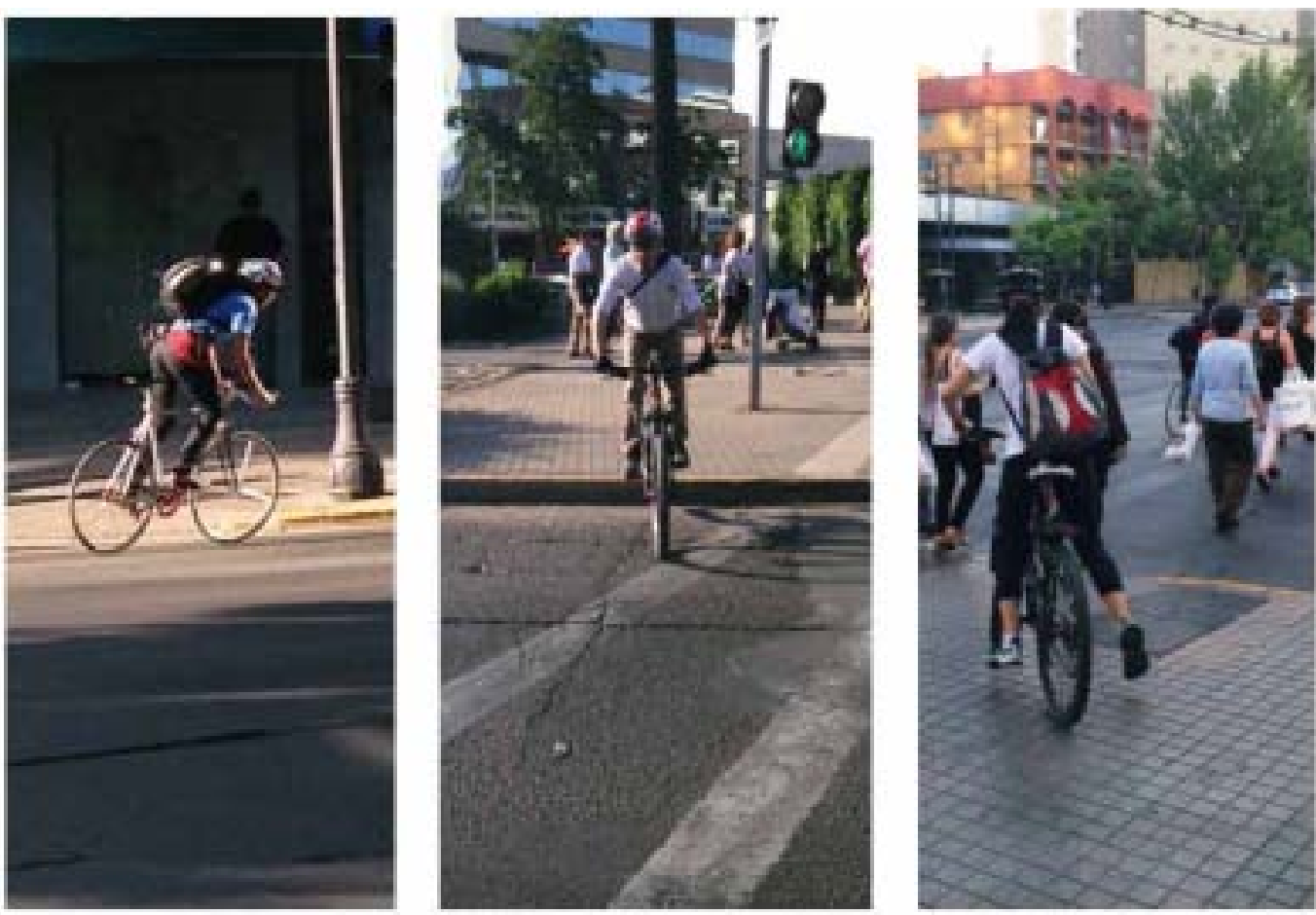

Figura 3. Fotografías extraídas de video-grabaciones durante la observación de ciclovías y calles. Observamos el ajuste físico y mental de los ciclistas en su circulación por la ciudad. Saber mirar, re-pensar las distancias, descubrir y entrenar el cuerpo.

evadir, o dejar pasar. De ello depende evitar accidentes como el que narra María durante un acompañamiento en bicicleta:

"me caí, me saqué la cresta[me pegué fuerte]... venía por la calle en Providencia, subiendo, con Manuel Montt... fue justo ahí donde está el metro, que cruza harta gente por el medio, no venían autos pero venía yo, por el lado izquierdo de los autos, y como no venían autos un peatón, como que no me vio... como que se le invisibilizan las bicis, y venía yo, a una velocidad relativamente rápida, y el gueón [tipo] llegó y cruzó, y como encima mío, y yo no alcance a hacer nada, lo choqué y yo salí volando, salí volando de lado y caí como con la cabeza con el casco, para al lado de la calle y dije 'conchadesumadre el casco sirve'... sentí el manso [gran] golpe, sentí como mi cabeza rebotó y ahí me asusté caleta [mucho]" " (María, 26 años, Estadística, Usuaria hace 1 año, extracto recorrido comentado).

Finalmente hay un proceso de ajuste físico, que tiene que ver con la tonificación muscular, el alza de temperatura, la transpiración, el cansancio, el rendimiento y, a un nivel más integral, con una mayor atención sobre el propio cuerpo, sus estados, necesidades, capacidades y transformaciones. Sergio comenta como en estos años de ciclismo ha descubierto en sus piernas músculos "que no sabía que tenía" (Spinney, 2006) y Luisa explica cómo ha logrado identificar y transitar a una velocidad que le permite llegar en un tiempo adecuado pero "sin sudar" a su lugar de trabajo: 
"Luego en el pedaleo hay una cosa rítmica, si tú no quieres transpirar, si tú no quieres cansarte, si tú no quieres llegar agitado al lugar donde vas, tu adosas el ritmo del pedaleo al latir de tu corazón, y vas a esa velocidad de crucero digo yo y llegas perfecto, llegas bien, y llegas como en equilibrio, llegas sin alterarte en ningún sentido" (Luisa, 45 años, directora de organización activista, usuaria hace más de 10 años).

Se trata, sin embargo, de experiencias vulnerables. El CU se despliega en una ciudad que no es "amable": donde otras entidades humanas (el automovilista, el microbusero, el peatón) y no humanas (el automóvil y el microbús, y sus magnitudes materiales, su potencial de daño) no están preparadas para asociarse a la bicicleta sin fricciones: bocinazos, frenazos, agresiones verbales, accidentes simples, graves y fatales, hoyos, cruces en lugares no habilitados, ciclovías serpenteantes o que se cortan sin anuncio, dan testimonio diario de como sucede en la práctica esta modalidad de transporte en la ciudad de Santiago.

Para manejarse en esas situaciones los entrevistados nos comentan sus aprendizajes. María, por ejemplo, nos explica que cuando circula por ciclovías y al costado tiene autos que pueden doblar por esta vía exclusiva hace contacto visual: "una amiga me dijo -no pases hasta que estés segura que el auto te vio-".

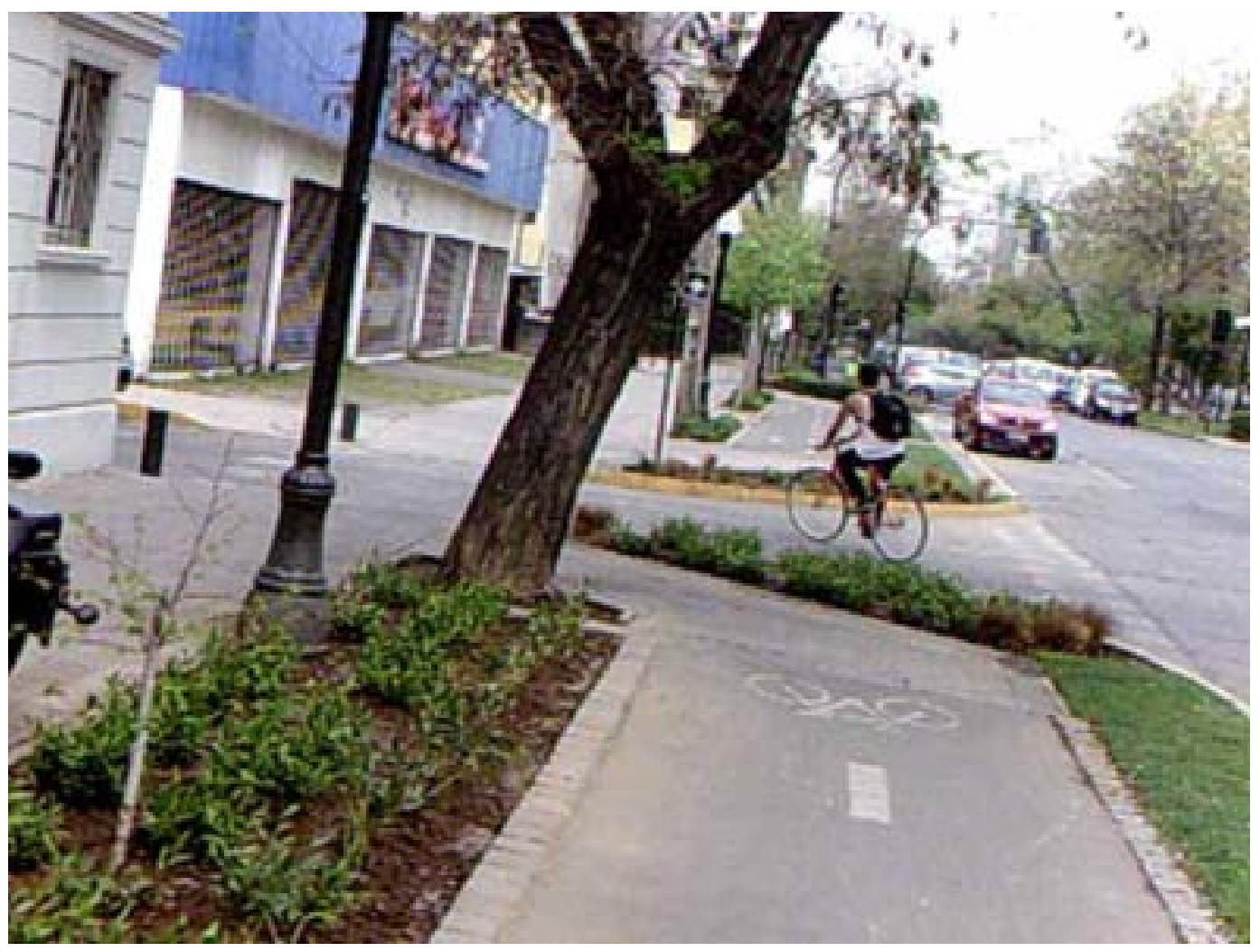

Figura 4. Fotografía de ciclovía que se interrumpe, segmento en el cual en la experiencia de Javiera no queda claro quién tiene la preferencia para circular 


\section{Formas de circulación: calles, ciclovías y aceras}

Fue especialmente evidente en los acompañamientos a los ciclistas que las formas de circulación jugaban un rol clave en la configuración de la experiencia de movilidad. Estas formas son múltiples: el ciclista urbano puede andar por ciclovías, por la calle, por la vereda, o por una combinación variada de ellas.

Asociadas a estas formas hay cualificaciones y valoraciones. Algunos informantes reclaman el uso de la calle ante el de las ciclovías, no sólo porque la insuficiencia, mal diseño y desintegración de estas últimas impiden un transporte eficiente y seguro, sino porque segregan al ciclista, lo alejan de la calle y le impiden ejercer su derecho. Al "bajar a la calle" el ciclista urbano performa la propuesta política que promueve: ser un medio de transporte eficiente en el uso del espacio urbano, ecológico en su traza y uso energético y que permite autonomía y control del propio tiempo. Sucedió así con Javiera:

"Yo siento que la gente que ocupa la bicicleta y anda por la calle está haciendo un uso mucho más eficiente del espacio de la ciudad. Porque... tú vas por la calle y ves, no sé, diez vehículos y en cada vehículo va una persona, son vehículos gigantes y ocupan toda la calle, y la calle es de todos... Entonces eso también he aprendido, aunque con mucho temor por los atropellos... tengo que andar por la calle sí o sî́" (Javiera, 26 años, Licenciada en Historia, usuaria hace 2 años).

Pero estos ciclistas urbanos no bajan espontáneamente a la calle, no todos al menos. En la actividad y en contacto con otros aprenden a afectarse con la importancia de hacerlo. Podemos reconocer así en la trayectoria de los ciclistas distintas "etapas" según las formas de circulación que han seguido. El relato de Carolina lo ilustra:

"Partí en la vereda, pero me duró muy poco y luego empecé a tomar las calles. Pero las grandes avenidas no las tomaba. Por ejemplo, me costó mucho tomar la avenida Alameda. Pero ahora soy un vehículo más dentro de la Alameda, entremedio de las cuatro pistas, me da lo mismo" (Carolina, 28 años, Actriz, usuaria hace 3 años).

El ciclista urbano puede ir apropiándose de nuevas circulaciones gradualmente: tener una "primera etapa de vereda", después una de calles pequeñas, de calles más transitadas, e incluso luego de mucho esfuerzo y aprendizaje tomar "las grandes avenidas como la Alameda" -la principal arteria capitalina-, y volverse un vehículo más, ocupando el mismo espacio que podría ocupar un automóvil o un bus, adelantándolos por el costado cuando se forman atascos, equilibrando la bicicleta con los pies. La circulación que privilegia la calle muchas veces valora negativamente el uso de la vereda por otros ciclistas urbanos:

"Si uno va por la vereda, igual está infringiendo el derecho de los peatones, y la vereda es para los peatones y la bicicleta... no sé cómo se llama... pero al ser un vehículo, tiene que andar por la calle" (Javiera, 26 años, Licenciada en Historia, usuaria hace 2 años).

El ciclista urbano ocupa espacio, la controversia está en ¿cuál espacio ocupar?, ¿el de los vehículos motorizados (calles) o el de las personas (veredas)? La decisión pasa para algunos porque el ciclista urbano moviliza un ideal de justicia: ¿quitarle espacio a quien ya tiene poco espacio o quitarle espacio a quienes ya tienen mucho? 
“si tú andas por la vereda, estás restándole un espacio a quienes tienen menos espacio, entonces es una cuestión de solidaridad también" (Camila, 27 años, Diseñadora, usuaria hace 6 años).

En la elección de circulaciones también entran en juego aspectos prácticos: características materiales que permiten conformar cierto ciclista y que a la vez limitan la activación de otros. El subir y bajar constante de la vereda puede implicar incomodidad en el viaje, impidiendo la realización del ciclista buscado, uno veloz y eficiente:

"la vereda me incomoda por tener que andar bajando y subiendo, bajando y subiendo, más que la gente. Y también creo que es una falta de respeto para un peatón que pase un ciclista rajao [veloz] al lado de ellos, no así pa' los autos." (María, 26 años, Estadística, usuaria hace 5 años).

Como nos enfrentamos a un arreglo múltiple, en el que distintas entidades se enfrentan (se asocian, colaboran, pero también chocan y entran en tensión) no es extraño reconocer una serie de interferencias y problemas para circular. Como en Santiago el principal vehículo es el transporte motorizado (automóviles, taxis, microbuses), algunos ciclistas reclaman no sentir un espacio propio reconociéndose en una existencia intermedia de "medio-peatón, medio automóvil". En ese sentido, por más que un ciclista quiera ir por la calle, hay ocasiones en que esa modalidad no puede ser activada, especialmente por los menos avezados:

"En Avenida Ossa... Vespucio, iba por la vereda porque no hay espacio como que los autos son muy locos ahí. Y después por la ciclovía" (Enrique, 25 años, Antropólogo, usuario hace 3 años).

Hay ciclistas urbanos que privilegian configurar una percepción de seguridad sobre la velocidad y la eficiencia y entonces invierten en un viaje que conecta ciclovías y veredas y que evade calles sin espacio, en las que circulan autos a mucha velocidad.

La falta de normativas claras es también invocada por los ciclistas como una de las razones para este uso mixto de espacios, que muchas veces genera interferencias entre las diferentes modalidades de transporte (ciclistas-automovilistas, ciclistas-peatones),

"Eso que te decía que estamos como en un limbo, como que no estamos institucionalizados totalmente, entonces por ejemplo si los ciclistas están en la vereda el correlato contrario es que también de repente hay peatones en la ciclovía. Las ciclovías no son tan respetadas y tampoco son tan buenas" (Enrique, 25 años, Antropólogo, usuario hace 3 años).

Incluso en las ciclovías parecen no existir siempre acuerdos colectivos:

"De los autos no, nadie me huevea [molesta], no he tenido problemas... en general me pasa mas con... me pongo más pesada, en... cuando yo voy en la ciclovía, yo creo que me es más fácil adaptarme a la calle, donde yo sé que tengo que cumplir ciertas reglas... que cuando estoy en la ciclovía que siento que nosotros tenemos el derecho de todo, y no se poh, se pone una moto y yo me emputezco[molesto]" (Extracto recorrido comentado María, 26 años, Estadística, usuaria hace 1 año).

Tampoco parece haber claridad con respecto al uso de las ciclovías por parte de la normativa. Contrario a la modalidad aquí descrita, en la señalética de la fotografía siguiente, la 

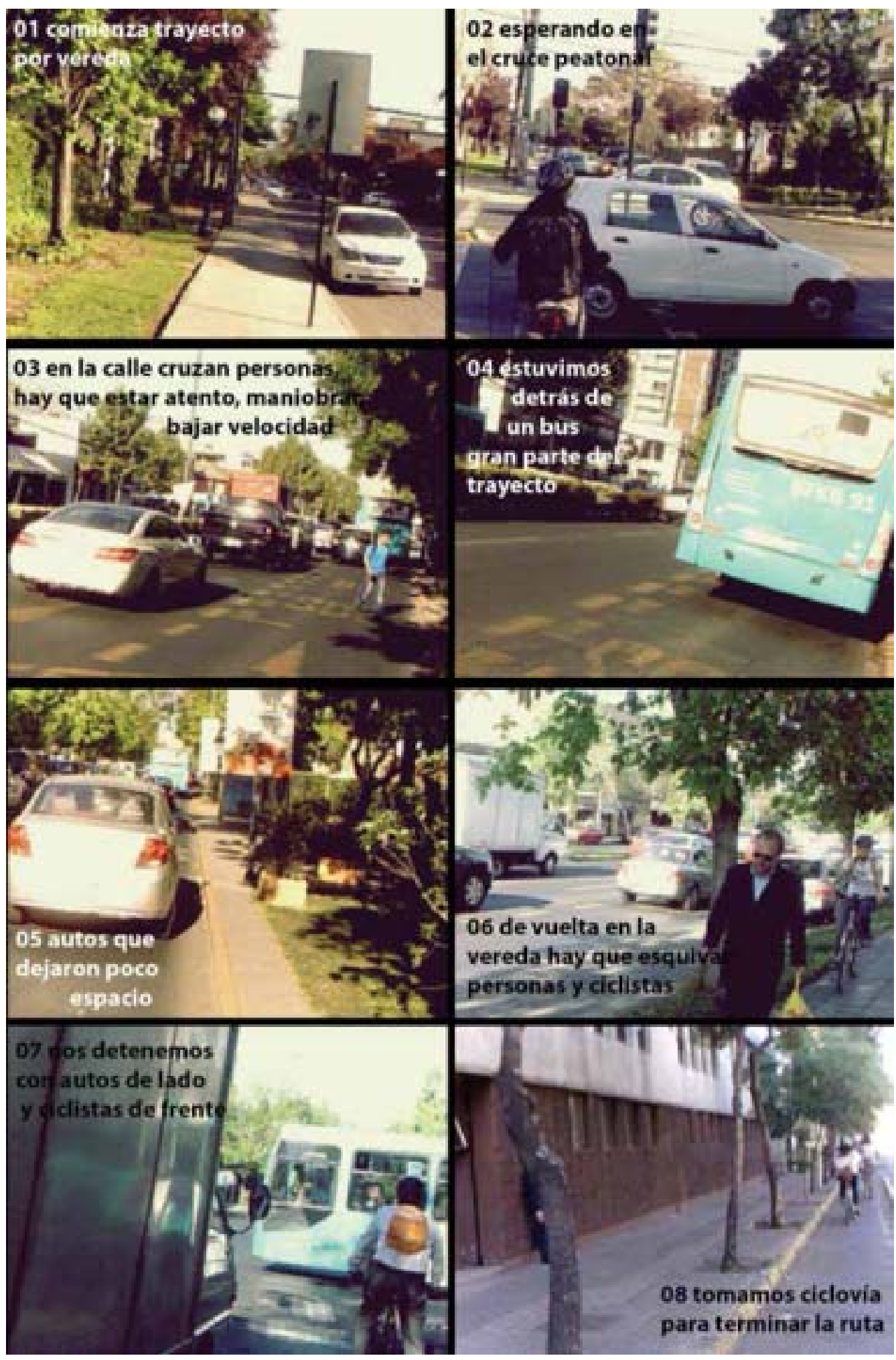

Figura 5. Extractos de acompañamiento a ciclista 


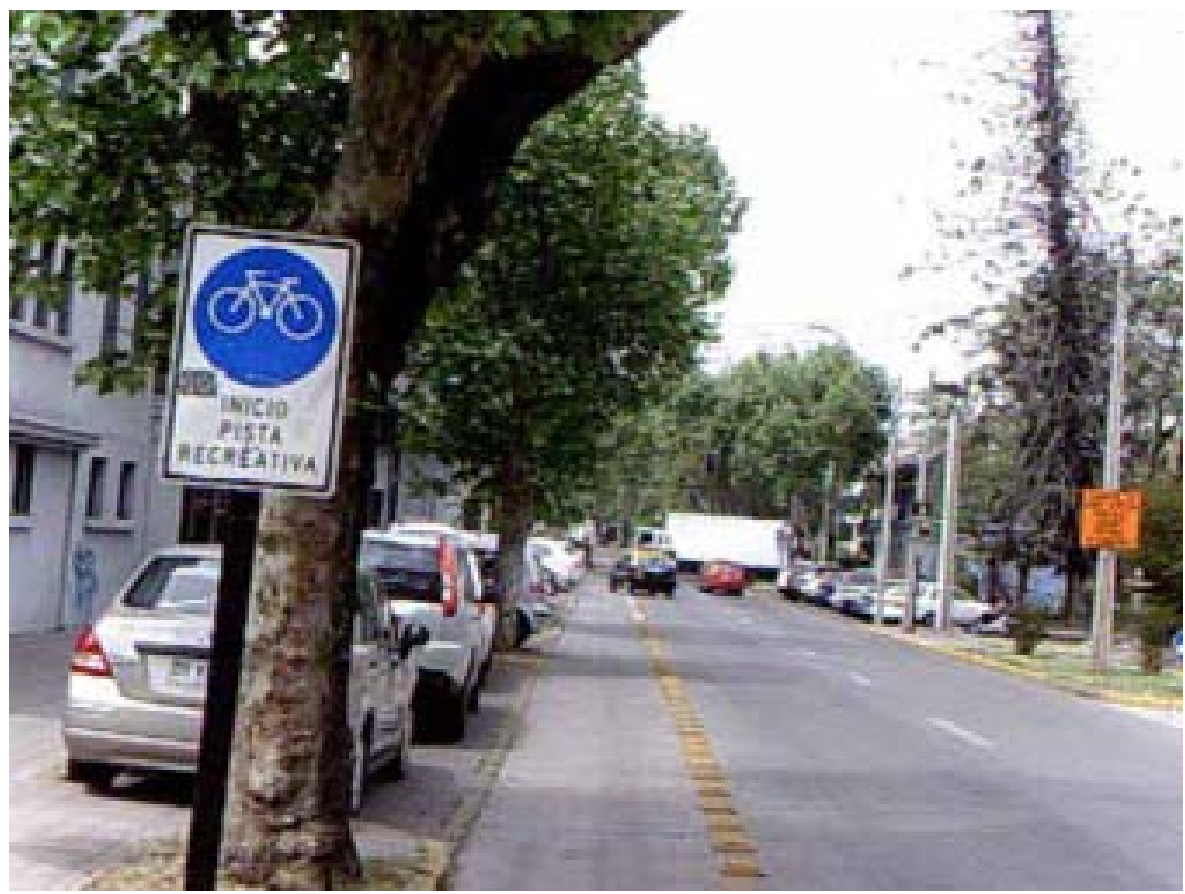

Figura 6. Señalética clasificando el ciclismo urbano como actividad recreativa y no de transporte

ciclovía es clasificada por la dirección de tránsito como una pista de uso recreativo:

\section{Las representaciones del ciclismo urbano: Entre los principios neoliberales y los de la sustentabilidad ambiental}

Más allá de logocentrismos (Domenech y Tirado, 1998), es un "hecho" que el CU es sustentable porque no contamina, y es eficiente en el uso del espacio urbano, Pero también el CU es sustentable porque parte importante de los ciclistas urbanos y activistas lo definen así y difunden, promueven y organizan datos, relatos y actividades alrededor de ello. Carla, por ejemplo, es una vocera eficiente de esta causa: describe a la bicicleta como un medio que utiliza menos espacio por persona transportada, no requiere de energía externa para su funcionamiento sino que opera con "la propia tracción del ciclista" y, además, no contamina como consecuencia de su actividad:

"Tu energía la estás utilizando en tu propio transporte, vas tú... es tu sinergia lo que te moviliza, no es una energía externa. Entonces... tiene que ver como con una concepción de las energías, de las energías renovables y del reciclaje, como del reutilizar, en el fondo, en el auto tú estás necesitando de un agente externo que moviliza el auto, que en el fondo es la bencina, que contamina, entonces, estás gastando la energía que se produce al producir la bencina y contaminando al mismo tiempo. En cambio, en la bici es una energía que se renueva, que tú reutilizas todos los días... no gastas" (Carla, 26 años, Profesora de Teatro, usuaria hace 2 años).

Como ilustran la siguiente gráfica (figura 7), las propias organizaciones o colectivos 

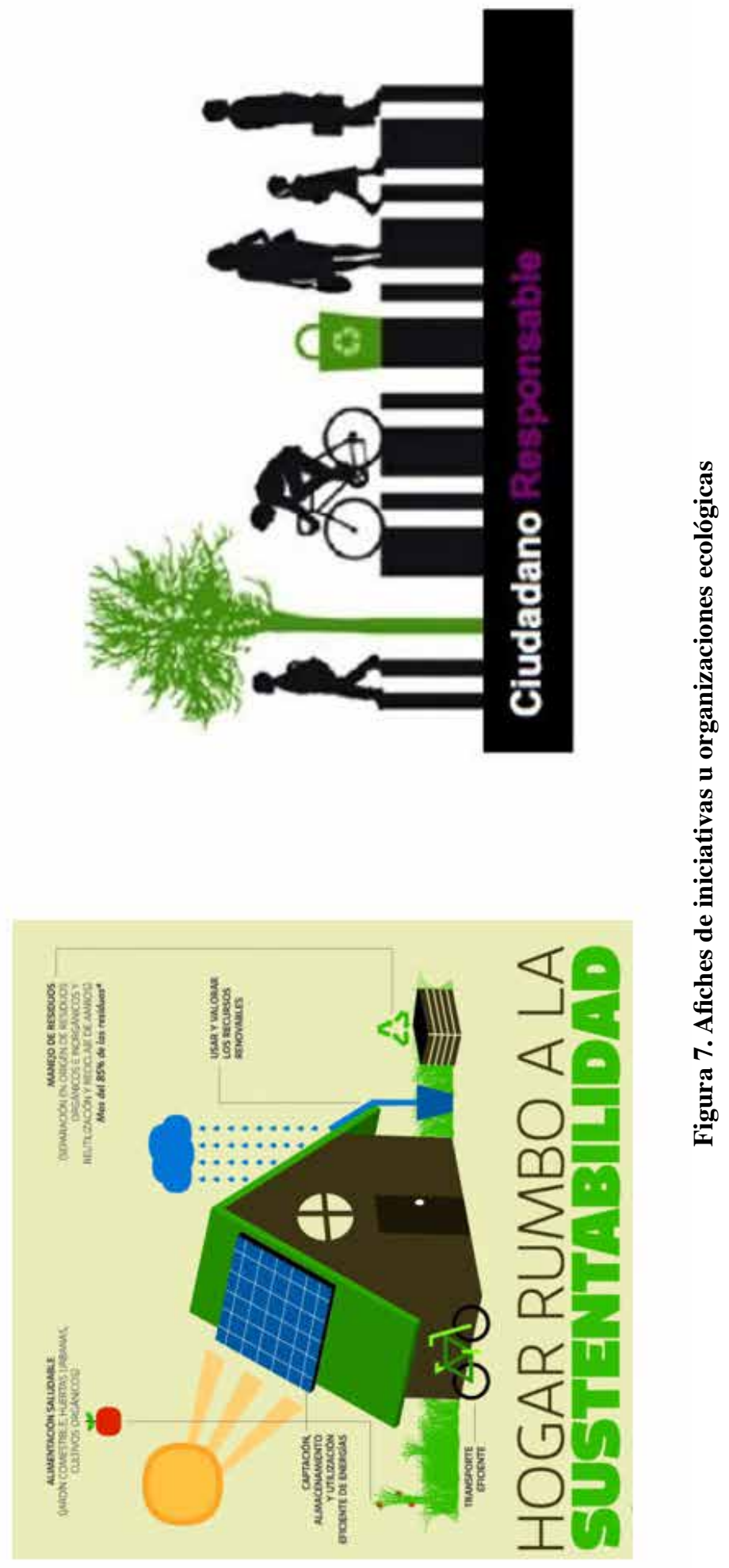
que promueven la ciudadanía ecológica y la sustentabilidad incluyen al ciclista urbano para difundir visiones de lo verde.

Según algunos de nuestros informantes el CU es sustentable -y político- en un segundo sentido: permitiría cierta independencia del individuo con respecto al principal mecanismo cooptador que tiene el sistema capitalista de mercado: controlarlo como consumidor. Argumentan que el ciclista no paga por transitar como sí lo hacen los vehículos motorizados (patente, tags), no requiere de permisos (de circulación, revisión técnica), "no paga para hacer funcionar su vehículo, no consume" y, por lo tanto, goza de cierta autonomía con respecto a "este modelo del libre mercado, de las grandes corporaciones, de seres humanos dependientes" que "solo interactuar con el mundo es pagando":

"Alguien que decide usar la bicicleta es alguien sumamente poco atractivo, porque a ese huevón no le puedes vender, ese huevón ya se mueve solo, ese huevón puede arreglar su bici solo, la puede cambiar si quiere, o sea, no hay control sobre esa persona... ni siquiera le puedo negar la movilidad" (Camilo, 35 años, Activista y Diseñador, usuario hace 15 años).

La dimensión política del CU también moviliza una propuesta de ciudad y más aún, una propuesta de sociedad. A aquella dependencia de la bicicleta en la energía humana se le asocia la capacidad escueta y aún insuficiente de "humanizar la ciudad", al permitir el reemplazo de "máquinas (autos) por personas (ciclistas)". La bici-movilidad, sería una tecnología de transporte a "escala humana", a "escala natural", que reduce el número de autos en circulación y aumentaría el de personas, de relaciones sociales, e incluso propiciaría la salud y la afectividad. ${ }^{4}$

"la bicicleta es un dispositivo, generador de conciencia ecológica, social, humana en general, si tú lo ves así como súper objetivamente y dices qué es lo que yo veo cuando salgo a las calles, cuál es tu impresión de ciudad, tú ves cemento, vías de cemento y autos por doquier. Cuando tú vas cambiando autos y buses por personas que se mueven a pie, en bicicleta, en triciclos, en patín, en patineta, en carro, en bici taxi, en lo que sea, a energía humana, tú lo que estás haciendo es humanizando la ciudad, cambiando máquinas por personas" (Luisa, Directora de organización activista, 45 años, usuaria hace más de 10 años).

La bici-movilidad estaría al centro de una ciudad y sociedad más limpia, más amable, más simple, menos consumista, más austera, menos "entregada al sistema", más consciente de su actividad, más cuidadosa, más alegre, más relajada, más colaborativa, más orientada al bien común y menos al interés individual. Una "ciudad más viva", compuesta por "ciudadanos". En contraposición, el paradigma de la auto-movilidad imperante, se signa como nocivo, ruidoso, violento, rabioso, triste, aislado, dañino, segregador y en lamentable expansión sostenida. En la apreciación de Sergio:

"Los autos se lo comen todo, se comen las calles, las veredas, se comen las plazas. Los niños no tienen donde jugar. [...] De verdad es un aporte no ocupar auto ... el auto es satisfacción personal no más, es una necesidad personal que satisfaces, pero haces un montón de daño en todo sentido, añades congestión, añades ruido, eh, no sé, encuentro que los autos son violentos. [...] Con la

4 Es interesante hacer notar que en la comparación al automóvil estos discursos purifican el objeto (la bicicleta) obviando su rasgo tecnológico. 
bicicleta te sientes como amistoso con la naturaleza porque además, qué bonito! y caminas y la puedes dejar al lado y te sientas..." (Sergio, 27 años, Profesor de Lenguaje, usuario hace 2 años).

Estos no son los únicos principios y prácticas que componen la cultura de la bici-movilidad en Santiago. Si observamos las motivaciones que llevan a optar por esta alternativa de transporte, los entrevistados relevan la autonomía, la independencia y la eficiencia en el uso del tiempo que trae aparejado el ciclismo. Así, junto con una ontología política alternativa que subraya la interdependencia y responsabilidad entre humanos y medioambiente, y aboga por una relación amorosa y pacífica entre ellos, se enarbolan principios neoliberales asociados a libertad y elección individual:

"Esa libertad la aprendí, o sea, tomé conciencia de ella, realmente cuando empecé a andar en bicicleta, y cuando noté que yo no dependía ni de ninguna marcha que se cruzara entremedio del tránsito, ni de los carabineros, ni de los retrasos de las micros, ni ningún problema, y que yo me mandaba sola, lo único que necesitaba era un kit de supervivencia en el caso de que pinchara la rueda y listo" (Carolina, 28 años, Actriz, usuaria hace 3 años).

"Andando en bicicleta puedes ir eligiendo diferentes rutas, ir a distintos lugares y tienes la facilidad de parar, de parar en algún lugar que te parezca interesante ... Yo creo que la ciudad que aparece en bicicleta es la que yo puedo elegir" (Enrique, 25 años, Antropólogo, usuario hace 3 años).

Estos extractos indican que la autonomía que ofrece la bici-movilidad parece propiciar nuevas o más experiencias urbanas (Enrique, Sergio) pero también estaría favoreciendo la desvinculación del ciclista con su entorno o la reducción de la experiencia urbana a un asunto de elección individual. Algunos, como Sergio, aun significan su bici-movilidad como una performance política en oposición a los regímenes de transporte dominantes. Pero otros, como Carolina, parecen estar desvinculándose de la ciudad montados en su bicicleta: evitando el transporte colectivo, la interacción con otros ciudadanos, el roce y la fricción consustanciales a la vida urbana. Tanto para quienes promueven propuestas alternativas de individuo y sociedad como para los que no, esta ambigüedad revela la penetración de lógicas neoliberales de vida y convivencia en esta sociedad.

\section{Conclusiones}

En este artículo intentamos mostrar algunos elementos que organizan la práctica del ciclismo urbano en Santiago de Chile, donde ha emergido como una alternativa de movilidad en desarrollo explosivo. Aquí muchas personas han tenido que "aprender a volverse ciclistas" e insertarse en un sistema o ensamblaje de transporte -que incluye a automóviles, buses, peatones- que no integra esta forma de movilidad coordinada ni automáticamente, sino que con bastante fricción e interferencias.

Desde un enfoque praxiográfico seguimos una modalidad de investigación etnográfica distribuida, corporalizada y móvil centrada en la circulación de personas y objetos por el centro de la ciudad, y las interacciones y vínculos con distintos elementos que tienen lugar en esa trayectoria, los espacios por los que pasan los ciclistas, sus aprendizajes y ajustes.

Sostuvimos que para comprender este modo de actividad no bastaba con conocer las características de los usuarios de la bicicleta, su perfil socio-demográfico, o las razones que motivan y justifican la adopción de esta forma de movilidad. El análisis de relatos de ciclistas y de notas de campo etnográficas y auto-etnográficas nos permitió constatar que 
el ciclismo urbano no es resultado exclusivo de un individuo y su trabajo subjetivo, ni de una estructura de transporte, sino que es un logro colectivo. Al estudiar esta práctica "en situación", vimos cómo el ciclismo urbano es el efecto de una red de relaciones y que la capacidad de agencia del ciclista no termina en los límites y recursos que él mismo percibe, sino que ella es amplificada, delimitada, facilitada u obstaculizada por otros individuos, objetos y materialidades. En ese sentido, mostramos que la práctica ciclista no es meramente humana, en ella intervienen materialidades, objetos y tecnologías. Y es en interacción con entidades así de heterogéneas que el ciclista se ajusta a y se afecta por esta actividad. Con ello quisimos enfatizar que estas otras entidades no solo generan representaciones del ciclista, sino que construyen su realidad. Construyendo, por ejemplo, determinadas ciclovías para su tránsito, define la viabilidad de esta alternativa de movilización, sus rutas, ritmos, tiempos y riesgos.

Profundizando los hallazgos de otros estudios que han examinado el rol del cuerpo (Larsen, 2014. Spinney, 2006) y de dispositivos tecnológicos en la práctica del ciclismo (Jungnickel; Aldred, 2014), en esta investigación describimos algunos de los elementos -humanos y materiales- que contribuyen a activar esta forma de movilidad en la ciudad. Mostramos así la importancia de "armarse la ruta"; el rol de los otros, que invitan, presentan, sirven de modelo y hacen viable esta modalidad de viaje; el papel que juega la máquina a la hora de producir una experiencia grata -que, dependiendo del usuario, puede estar definida por la seguridad, la rapidez, la comodidad, etc.-. También describimos el proceso de descubrimiento y entrenamiento del cuerpo, el ajuste físico y mental por los que pasan los ciclistas urbanos.

Para ello, no sólo mostramos un listado de elementos humanos y materiales que componen el ciclismo urbano en Santiago; también describimos cómo estos se organizan, o -a veces- chocan y entran en conflicto. El ciclismo urbano en Santiago produce experiencias vulnerables, porque la ciudad no es amable, porque las entidades no están preparadas para una asociación sin fricciones. La estabilización del ciclismo urbano implica así un proceso práctico, iterativo en el que los ciclistas aprenden a afectarse, a participar, y a relacionarse con otras entidades.

Algunas de las formas en que estos elementos se organizan son movimientos de enrolamiento y concientización, estrategias de manejo y tácticas de cuidado y acciones de reacción u oposición a otras modalidades de transporte. Un ejemplo de estas diversas maneras de asociarse lo trabajamos al analizar las formas de circular: vimos distintos vínculos con las ciclovías, las calles y veredas. Ciclistas que procesualmente se van apropiando de nuevas circulaciones, que pasan por etapas de veredas, de ciclovías, algunos que "bajan a la calle". Y vimos el rol de estas elecciones y sus propiedades materiales a la hora de dar forma a diferentes ciclismos urbanos: unos "seguros", otros "veloces y de adrenalina", y formas híbridas que combinan distintos elementos. Estos hallazgos relevan la importancia de no atribuir a priori propiedades a los componentes de las prácticas que estudiamos y dejar que el ejercicio etnográfico nos indique cómo actúan en común y qué esfuerzos deben hacer para mantener la práctica estable en el tiempo de modo que la podamos identificar como tal.

Atendiendo al carácter normativo de la sustentabilidad, también expusimos una breve ontología política de la bicicleta que comporta una propuesta de movilidad, de ciudadanía y de sociedad ambigua que parece promover ideas de sociedad e individuo alternativas pero que difunde también valores propios de un régimen neoliberal.

No solo la conveniencia, flexibilidad, eficiencia y salud orientan la elección de esta alternativa de movilidad (Fernández-Heredia y otros, 2014. Green y otros, 2012) sino también atributos que tenderían a desvincular al ciclista de la vida pública, como la autonomía, independencia y eficiencia en el uso del propio tiempo.

En la línea de los aportes de investigaciones que examina la bicicleta como símbolo del movimiento verde o como una práctica que exhibe y difunde un estilo de vida "ecológico" (Green y otros, 2012. Horton, 2006) los discursos y estilos de vida de los ciclistas que par- 
ticiparon en nuestra investigación también signan al ciclismo como una práctica moralmente mejor que el transporte motorizado. La bici-movilidad es incluida en una propuesta de sociedad y ciudadanía que incluye distintas prácticas, estilos y opciones de vida (reciclaje, trueque, comercio justo, vida local, civilidad, transparencia, calidad de vida, nutrición sana, etc.) que podríamos sintetizar en una 'ciudadanía ecológica', es decir, consciente de la interdependencia de entidades sociales y naturales y de distintas generaciones. Sin embargo, por la posición aún marginal (Aldred, 2013) de esta alternativa de movilidad dentro del sistema de transporte y de la cultura moral de los santiaguinos, en la práctica, el ciclismo urbano se realiza aquí con altas dosis de tensión, alerta, vigilancia, estrés, conflicto y riesgo. Pese a ello, la etnografía nos permitió identificar que la dimensión ecológica del ciclismo urbano no depende solo de la conciencia del ciclista sino fundamentalmente de la concreción diaria de la misma práctica -trasladarse en bicicleta no contamina ni gasta, independientemente de que este sea o no la motivación de su usuario.

\section{Bibliografía}

BANCO INTERAMERICANO DE DESARROLLO

2015 Ciclo-inclusión en América Latina y el Caribe: Guía para impulsar el uso de la bicicleta. Banco Interamericano de Desarrollo.

BERNASCONI, Oriana

2013 Etnografía multi-sitio para una sociología no antropocéntrica, relacional y pragmática del individuo. Presentado en Séptimas jornadas sobre etnografía y métodos cualitativos, Buenos Aires.

2015 ¿Qué nos hace ser individuos? Por un enfoque post-humano, pragmático y relacional. Athenea digital, 15(2), 205-229.

CALLON, Michel

1995 Algunos elementos para una sociología de la traducción. En J. M. Iranzo (Ed.), Sociología de la Ciencia y la Tecnología. CSIC-Departamento de Publicaciones.

2008 Economic Markets and the Rise of Interactive Agencements. En T. Pinch \& R. Swedberg (Eds.), Living in a Material World: Economic Sociology Meets Science and Technology Studies (pp. 29-56). Cambridge: The MIT Press.

CAULFIELD, Brian

2014 Re-cycling a city-examining the growth of cycling in Dublin. Transportation research, 61, 216-226.

COLLECT GFK

2013 Estudios Tracking Calidad de Servicio Transantiago. Santiago: Collect GFK.

DILL, Jennifer; CARR, Theresa

2003 Bicycle commuting and facilities in major US cities: if you build them, commuters will use them. Transportation Research Record: Journal of the Transportation Research Board, (1828), 116-123.

DOMÈNECH, Miquel; TIRADO, Francisco

1998 Sociología Simétrica. Barcelona: Gedisa.

ELLIS, Carolyn; ADAMS, Tony; BOCHNER, Arthur

2010 Autoethnography: An Overview. Forum: Qualitative Social Research, 12(1).

FERNÁNDEZ-HEREDIA, Álvaro; MONZÓN, Andrés; JARA-DÍAZ, Sergio

2014 Understanding cyclists' perceptions, keys for a successful bicycle promotion. Transportation research, 63, 1-11.

GARFINKEL, Harold

1967 Studies in Ethnomethodology. Cambridge: Polity Press.

GOMART, Emilie; HENNION, Antoine

1999 A sociology of attachment: music amateurs, drug users. The Sociological Review, 47(S1), 220-247.

GREEN, Judith; STEINBACH, Rebecca; DATTA, Jessica

2012 The travelling citizen: emergent discourses of moral mobility in a study of cycling in London. Sociology, 46(2), 272-289. 


\section{HADDERS, Hans}

2009 Enacting death in the intensive care unit: medical technology and the multiple ontologies of death. Health, 13(6), 571-587.

\section{HENNION, Antoine}

2001 Music Lovers Taste as Performance. Theory, Culture \& Society, 18(5), 1-22.

HORTON, Dave

2006 Environmentalism and the bicycle. Environmental Politics, 15(1), 41-58.

JUNGNICKEL, Katrina; ALDRED, Rachel

2014 Cycling's sensory strategies: How cyclists mediate their exposure to the urban environment. Mobilities, 9(2), 238-255.

LAW, John

2009 Actor Network Theory and Material Semiotics. En B. S. Turner (Ed.), The New Blackwell Companion to Social Theory (pp. 141-158). Wiley-Blackwell.

MARCUS, George

1995 Ethnography in/of the World System: The Emergence of Multi-Sited Ethnography. Annual Review of Anthropology, 24(1), 95-117.

MINISTERIO DE TRANSPORTES Y TELECOMUNICACIONES.

2012 Plan Maestro de Transporte Santiago 2025. Santiago: Ministerio de Transportes y Telecomunicaciones.

MOL, Annemarie

2003 The Body Multiple: Ontology in Medical Practice. Durham: Duke University Press Books.

2010 Actor-Network Theory: Sensitive terms and enduring tensions. Kölner Zeitschrift für Soziologie und Sozialpsychologie, 50(1), 253-269.

RIETVELD, Piet; DANIEL, Vanessa

2004 Determinants of bicycle use: do municipal policies matter? Transportation Research Part A: Policy and Practice, 38(7), 531-550.

ROSEN, Paul; COX, Peter; HORTON, Dave

2007 Cycling and society. Gran Bretaña: Ashgate Publishing.

SECTRA

2014 Actualización y recolección de información del sistema de transporte urbano: Encuesta Origen Destino Santiago 2012. Santiago: SECTRA.

SNIZEK, Bernhard; NIELSEN, Thomas; \& SKOV-PETERSEN, Hans

2013 Mapping bicyclists' experiences in Copenhagen. Journal of Transport Geography, 30, 227-233.

SPINNEY, Justin

2006 A place of sense: a kinaesthetic ethnography of cyclists on Mont Ventoux. Environment and Planning D, 24(5), 709.

2011 A chance to catch a breath: Using mobile video ethnography in cycling research. Mobilities, 6(2), 161-182.

STEINBACH, Rebecca; GREEN, Judith; DATTA, Jessica; EDWARDS, Phil

2011 Cycling and the city: a case study of how gendered, ethnic and class identities can shape healthy transport choices. Social Science \& Medicine, 72(7), 1123-1130.

THRIFT, Nigel

2008 Non-Representational Theory: Space, Politics, Affect. Londres: Routledge.

WATTS, Laura; URRY, John

2008 Moving methods, travelling times. Environment and Planning D: Society and Space, 26(5), 860-874. 